\title{
The Application of the Value Engineering Theory in the Optimization of the Foundation Pit Supporting Scheme
}

\author{
Jing Ning Yan \\ Civil Engineering and Architecture School of Nanchang Hangkong University, Nanchang, Jiangxi, \\ 330063, China \\ 2248602417@qq.com
}

Keywords: Value engineering; The foundation pit supporting scheme; Optimization; Type; Trait

\begin{abstract}
The foundation pit engineering is a complicated system engineering.The reasonable foundation pit supporting scheme is the key to ensure the construction quality of foundation pit engineering. The trait of the foundation pit engineering includes the strong regional trait,relatively large risk, strong personality,high accident rate, a very comprehensiveness, high quality requirement and so on. The type of the foundation pit supporting scheme are as follows: the slope excavation, the soil nailing wall, the steel sheet pile support, the continuous underground wall, the reinforced cement soil retaining wall, the row pile support, the deep mixing pile retaining, the bolt support, the composite supporting structure. The value engineering is the modern management technology of combination of technology and economy. It is a effective method to reduce the cost and improve the economic benefit. The application of the value engineering theory to optimize supporting scheme can reduce the construction cost and improve the economic benefit. The engineering example shows the application of the value engineering theory in the optimization of the foundation pit supporting scheme.
\end{abstract}

\section{Introduction}

With the acceleration of the urbanization process and the expansion of the city scale,the city construction land becomes nervous increasingly. More and more requirements of city land utilization rate is high. A large number of high-rise, super high-rise building constructs in the city. Such as the 81 storey International Trade Building or Cetra Building in Beijing, up to 330 meters high.

In addition, the use of the subway station, underground garage, underground shopping malls, underground warehouse and other underground engineering in the city is becoming more and more frequent. Such as the Qian Hai Wan Metro Station in Shenzhen Metro Line 11 is the largest in Asia, with the excavation length of 830 meters. Along with the construction of these projects, a large number of the foundation pit engineering appear. The trait of the foundation pit engineering in our country is as follows.[1]

Strong regional trait. The regional trait of the rock and soil engineering is strong. The foundation pit engineering belongs to the rock and soil engineering.Its regional trait is stronger. The construction of foundation pit engineering is significant difference in the soft clay, sand soil foundation, loess foundation engineering geological and hydrogeological conditions in different soil.The design and construction of the foundation pit supporting scheme should be suited to its measures to local conditions and be combined with the specific circumstances of development.

The risk is relatively large. The foundation pit engineering is temporary, safety stock is relatively small, so the risk is greater.[2]Monitoring should be the construction process of foundation pit engineering, and the emergency measures. During the construction process, once the danger, the need for timely rescue.[3] 
A strong personality.The foundation pit engineering is related to the engineering geological conditions and hydrogeological conditions.It also is related to the urban underground pipe network and the position of adjacent buildings, building foundation pit.

High accident rate. The construction period of the foundation pit engineering is long. From excavation to complete all the projects under the ground, often after rain, the surrounding pile load, vibration and many other adverse conditions. The randomness of the safety degree is big. Accidents are often unexpected. According to the statistics, the foundation pit engineering accident rate is generally accounted for about 20 percents of the number of foundation pit engineering, some city even accounted for about 30 percents.

A very comprehensiveness. The foundation pit engineering is a comprehensive engineering geological, geotechnical engineering, structural engineering and construction technology. It is a complex system engineering factors influence each other. It is not only the need of geotechnical engineering knowledge, also need to structure engineering knowledge, so the requirements of the design and construction of foundation pit, should have a comprehensive knowledge and experience.

High quality requirement. Usually the excavation area is the future of the underground structure construction area, sometimes part of the supporting structure of underground structure is permanent. But the quality of the underground structure will directly affect the upper structure. Therefore, the quality assurance of the foundation pit engineering will ensure the underground structure and the upper structure of the quality of the project, so as to ensure the creation of a good precondition for the quality of the building engineering.

The environmental effect is obvious. The excavation of foundation pit engineering is usually caused by underground water level ground stress field change and change, leading to the deformation of soil around the foundation, thus affecting the adjacent buildings, structures and underground municipal pipelines. The noise and dust caused by construction, earthwork and material transport will interfere with traffic.It have a greater impact on the surrounding environment and residents.

\section{The type of the foundation pit supporting scheme}

The foundation pit supporting scheme are the retaining, reinforcement and protection measure which is to ensure the safety of foundation pit construction and surrounding environment by the pit wall and the surrounding environment.[4]To the same foundation pit, using different support schemes, the final effect of the construction is different. So the suitable foundation pit supporting scheme selection is the key of the construction. The following common foundation pit supporting scheme is as follows.

The slope excavation.It is as follows: In the process of pit excavation, when the conditions are satisfied, the slope can be selected properly, so that after the excavation of foundation pit in the soil reinforcement and support conditions, depending on the soil strength, stable and maintain the stability of the foundation pit.[5]

The soil nailing wall. It refers to the use of nails or prestressed anchor to reinforce the foundation pit wall soil, and the injection of reinforced concrete revetment retaining structure.

The steel sheet pile support.It is manufactured by the hot rolling steel lock mouth or jaw.The connected steel sheet pile forms the steel sheet pile wall.It is widely used in retaining and water retaining.

The continuous underground wall. It refers to the use of special equipment in dredging, mud dug trench conditions, narrow and deep in the ground, and then the reinforcement cage concrete pouring, the formation of a continuous underground reinforced concrete wall seepage, retaining and bearing function.[6]

The reinforced cement soil retaining wall. Reinforced cement soil retaining wall is inserted into the $\mathrm{H}$ shaped steel in the soil cement pile in. The $\mathrm{H}$ shaped steel subjects to the lateral load. The cement soil has good impermeability. So it has good anti leakage effect of retaining and sealing.[7] 
The row pile support. It is a type of reinforced concrete columns spaced hole digging, drilling (punching) or PHC pipe pile as a retaining structure form of support.

The deep mixing pile retaining. It is with deep mixer in the cement soil and the input (powder) forced mixing, resulting in the formation of soil cement column and solid wall continuous lap. The functional analysis on the construction technology of the post pouring belt.

The bolt support. It is a technique of rock and soil stability of active reinforcement. [8] Anchor as its main technology, end anchored into the stability of the soil (rock) and the other end of the various forms of supporting structure is connected, and prestressed. Through the pull rod body, arousing deep formation potential, to maintain the stability of foundation pit.

The composite supporting structure. It refers to the use of a variety of supporting structure of foundation pit on the same foundation pit support. [9]

\section{The value engineering theory.}

It is also called value analysis.It is the modern management technology and economy closely and pay more attention to the economic benefits. Its key is the analysis of the core operations or functions of the product. The purpose is to improve the operation or the value of the products. It is a necessary function with the lowest life cycle cost operation or product contains the organization, rules of creative activity.It involves three basic factors of life cycle cost, function and value. It is a kind of engineering management theory. Its core idea is the least cost for the necessary function. The mathematical expression of the value engineering theory is Eq.1. [10]

$V=\frac{F}{C}$

$\mathrm{V}$ represents the value of the research object type. F stands for the function of the research object. C stands for the object of study of the cost, the life cycle cost.

\section{The application step of the theory of value engineering in the optimization of the foundation pit supporting scheme}

According to the characteristics of surrounding buildings and pipelines dense degree and importance, construction condition, type of foundation pit, all feasible scheme are designed. To determine the evaluation index and its weight function. To determine the degree of each scheme of each index score. The calculation of the function evaluation score of each proposal. To determine the functional coefficient of each scheme. To determine the cost coefficient of each scheme. To determine the value of coefficient of each scheme. The calculation of the value of the coefficient of each scheme is Eq.2.According to the numerical value of each scheme, the maximum value coefficient method is the optimal solution.

$V_{i}=\frac{F_{i}}{C_{i}}$

\section{The analysis of the engineering example}

The engineering situation. The project is located in the city district of room for city road, east and south, north and west to idle land for construction. The proposed site is alluvial plain. Silt and fine sand in the upper part of the site for the recent backfill. Terrain undulating. The basement layer is a layer. The excavation depth is 3.7 meters. This project is a temporary pit.

The alternative the foundation pit supporting scheme. According to the formation conditions, the excavation of the surrounding environment, the calculation area design and construction 
experience and combining theory.The foundation pit supporting scheme are as follows: The soil nailing wall(P1); the slope with hanging net sprayed concrete support(P2); the drilling pile(P3).

To determine the evaluation index and its weight function. Combined with the actual situation of the foundation pit,select the"technical feasibility $\left(A_{1}\right)$ 、 economy $\left(A_{2}\right)$ 、 safety and reliability $\left(A_{3}\right)$ 、 the complexity of the construction $\left(\mathrm{A}_{4}\right)$, environmental effects $\left(\mathrm{A}_{5}\right)$ " as functional evaluation index. According to the design institute、 owner、 contractor, accounted for $40 \%, 30 \%, 30 \%$ the proportion of comprehensive score, to determine the functional evaluation index weight as shown in Table 1 . The calculation of the functional evaluation index weight is Eq.3.

Table 1 The functional evaluation index weight table

\begin{tabular}{|c|c|c|c|c|c|c|c|}
\hline \multirow{2}{*}{$\begin{array}{l}\text { functional } \\
\text { evaluation } \\
\text { index }\end{array}$} & \multicolumn{2}{|c|}{ design institute } & \multicolumn{2}{|c|}{ owner } & \multicolumn{2}{|c|}{ contractor } & \multirow{2}{*}{$\begin{array}{c}\text { Weight } \\
\text { (B) }\end{array}$} \\
\hline & score $(\mathrm{S} 1)$ & $0.4 \mathrm{~S} 1$ & score $(\mathrm{S} 2)$ & $0.3 \mathrm{~S} 2$ & score (S3) & $0.3 \mathrm{~S} 3$ & \\
\hline A1 & 30 & 12 & 20 & 6 & 30 & 9 & 0.27 \\
\hline A2 & 20 & 8 & 30 & 9 & 20 & 6 & 0.23 \\
\hline A3 & 15 & 6 & 15 & 4.5 & 25 & 7.5 & 0.18 \\
\hline A4 & 15 & 6 & 15 & 4.5 & 15 & 4.5 & 0.15 \\
\hline A5 & 20 & 8 & 20 & 6 & 10 & 3 & 0.17 \\
\hline total score & 100 & 40 & 100 & 30 & 100 & 30 & 1 \\
\hline
\end{tabular}

On the basis of the weight function, using 10 point weighted scoring method, to meet the 5 functions of the 3 schemes were calculated respectively, the evaluation function of each alternative support schemes for foundation pit score as shown in Table 2.Calculating the function coefficients of each scheme are shown in Table 3.After calculation, the supporting scheme of cost and cost coefficient is calculated as shown in Table 4.The calculation of the value coefficient of each scheme are shown in Table 5.According to the plan and the value coefficient of the soil nailing wall, the value of coefficient is the largest, so the soil nailing wall is the optimal solution.

Table 2 The function evaluation score table of the scheme

\begin{tabular}{|c|c|c|c|c|}
\hline functional evaluation index & \multirow{2}{*}{ weight B } & \multicolumn{3}{|c|}{ function evaluation score } \\
\cline { 3 - 5 } & & P1 & P2 & P3 \\
\hline A1 & 0.27 & 10 & 6 & 6 \\
\hline A2 & 0.23 & 9 & 6 & 7 \\
\hline A3 & 0.18 & 9 & 7 & 7 \\
\hline A4 & 0.15 & 8 & 6 & 8 \\
\hline A5 & 0.17 & 10 & 7 & 6 \\
\hline tota1 score & & 9.29 & 6.35 & 6.71 \\
\hline
\end{tabular}

Table 3 The function coefficient calculation table of the scheme

\begin{tabular}{|c|c|c|c|}
\hline name & P1 & P2 & P3 \\
\hline total score & 9.29 & 6.35 & 6.71 \\
\hline function coefficient(F) & 0.416 & 0.284 & 0.3 \\
\hline
\end{tabular}


Table 4 The cost coefficient calculation table of the scheme

\begin{tabular}{|c|c|c|c|}
\hline name & P1 & P2 & P3 \\
\hline cost (million yuan) & 268.2 & 245.1 & 293.6 \\
\hline cost coefficient (C) & 0.332 & 0.304 & 0.364 \\
\hline
\end{tabular}

Table 5 The value coefficient calculation table of the scheme

\begin{tabular}{|c|c|c|c|}
\hline name & F & C & V \\
\hline P1 & 0.416 & 0.332 & 1.253 \\
\hline P2 & 0.284 & 0.304 & 0.934 \\
\hline P3 & 0.3 & 0.364 & 0.824 \\
\hline
\end{tabular}

\section{Summary}

The optimization of foundation pit supporting scheme is a complex and difficult work. It is difficult to quantify the evaluation index of the lot. Through the introduction of the theory of value engineering can be a lot of qualitative index quantitative analysis by weight. To avoid the subjectivity and arbitrariness. To achieve the objective, fair, comprehensive quantitative evaluation of the foundation pit supporting scheme.

\section{References}

[1] N.F.Mei,X.D.Luo,N.Jiang,X.Y.Fang,Z.W.Dai and H.Luo:Journal of Central South University(Science and Technology), Vol.44 (2013) No.5, p.1982.

[2] J. Xu and J.R.Song:Sichuan Building Science, Vol.39 (2013) No.1, p.332.

[3] Z.P. Liu,C.B.Fang,Q.L.Guo,L.M.Zhang and L.Meng: Technology and Economy in Areas of Communications, Vol.15(2013) No.5, p.32.

[4] Z.J.Xu: Deep foundation pit supporting technology collection (China Building Industry Press, China, 2012).

[5] H.X. Li: Shanghai Construction Technology, Vol.39(2013) No.1, p.53.

[6] C.M.Zhou and H.L.Zhang:Sichuan Building Science, Vol.39 (2013) No.4, p.259.

[7] X.Q.Yang:Shangxi Architecture, Vol.38 (2012) No.1, p.71.

[8] Z.J.Xie:Shangxi Architecture, Vol.39 (2013) No.2, p.49.

[9] L.G.Mao:Journal of Jinling Institute of Technology, Vol.29 (2013) No.2, p.37.

[10] J.D.Sun: Value engineering in construction project (China Building Industry Press, China, 2011). 